\title{
Effect of bio-functional MAO layers on the electrochemical behaviour of highly porous $\mathrm{Ti}$
}

\author{
A.C. Alves $^{\mathrm{a}, *}$, A.I. Costa ${ }^{\mathrm{a}}$, F. Toptan ${ }^{\mathrm{a}, \mathrm{b}, \mathrm{c}}$, J.L. Alves $^{\mathrm{a}, \mathrm{b}}$, I. Leonor ${ }^{\mathrm{d}, \mathrm{e}}$, E. Ribeiro ${ }^{\mathrm{d}, \mathrm{e}}$, R.L. Reis ${ }^{\mathrm{d}, \mathrm{e}}$, \\ A.M.P. Pinto ${ }^{\mathrm{a}, \mathrm{b}}$, J.C.S. Fernandes ${ }^{\mathrm{f}, \mathrm{g}}$ \\ ${ }^{\text {a }}$ CMEMS-UMinho - Center of MicroElectroMechanical Systems, University of Minho, Guimarães, Portugal \\ ${ }^{\mathrm{b}}$ Dep. Mechanical Engineering, University of Minho, Guimarães, Portugal \\ ${ }^{\mathrm{c}}$ IBTN/Br - Brazilian Branch of the Institute of Biomaterials, Tribocorrosion and Nanomedicine, UNESP, Campus de Bauru, Av. Eng. Luiz Edmundo Carrijo Coube, 14-01, \\ 17033-360 Bauru, SP, Brazil \\ ${ }^{\mathrm{d}} 3 B^{\prime}$ 's Research Group - Biomaterials, Biodegradables and Biomimetics, University of Minho, Guimarães, Portugal \\ e ICVS/3B's-PT Government Assoc. Laboratory, University of Minho, Braga, Guimarães, Portugal \\ ${ }_{\mathrm{f}}^{\mathrm{f}}$ Department of Chemical Engineering - Instituto Superior Técnico, University of Lisbon, Lisboa, Portugal \\ ${ }^{g}$ CQE - Instituto Superior Técnico, Lisboa, Portugal
}

\section{A R T I C L E I N F O}

\section{Keywords:}

Powder metallurgy

Porous Ti

Micro-arc oxidation

Corrosion

EIS

\begin{abstract}
A B S T R A C T
Ti foams are attractive for orthopaedic applications due to reduced Young's modulus and ability of bone ingrowth. However, poor corrosion behaviour and lack of bioactivity are yet to be overcome. In the present work, highly porous Ti samples were processed by powder metallurgy with space holder technique and bio-functionalized by micro-arc oxidation, resulting in nano/micro structured $\mathrm{TiO}_{2}$ surfaces containing bioactive elements. The electrochemical behaviour of these bio-functionalized highly porous Ti surfaces was evaluated through potentiodynamic polarization and EIS in physiological solution at body temperature. Results showed that biofunctionalization improved the corrosion behaviour of highly porous Ti. However, increased macro-porosity led to an increased corrosion rate.
\end{abstract}

\section{Introduction}

Ti-based materials are commonly used as orthopaedic and dental implant materials due to their properties, as excellent biocompatibility, high specific strength, high corrosion resistance, low density, and relatively low Young's modulus [1-6]. However, these materials still present the risk of implant aseptic loosening or bone failure, mainly due to stress-shielding effect that is caused by the inefficient load transfer from the implant to the bone [7-9]. The stress-shielding effect occurs due to the mismatch of Young's modulus between the implant material (Ti: 100-110 GPa, Ti6Al4V: $114 \mathrm{GPa}$ ) and human bones (4-30 GPa) $[3,7,8]$.

Porous Ti structures presenting open-cellular structure are being developed in order to decrease this mismatch but also to allow the newbone in-growth and the transport of body fluids [10-14]. Moreover, as reported by Jha et al. [15], open-cellular structures also show potential for drug delivery applications. One of the most suitable methods for processing Ti foams is space-holder technique. This method is cost-effective and allows to adjust the porosity level, pores geometry and pores size distribution [15-18].

Studies regarding characterization of porous metallic implants in terms of microstructural, mechanical and biological properties are widely reported in the literature [19-24]. However, reports on their electrochemical behaviour are still scarce $[1,22,23]$. Some studies showed that the corrosion behaviour of porous materials may be different from dense materials, mainly due to the existence of localized corrosion as a result of the stagnation of the electrolyte inside the pores $[22,23]$, or due to the differences in the nature and quality of the passive films formed on the outermost surfaces and on the inner pore surfaces [1].

Although $\mathrm{Ti}$ is the most biocompatible metallic material, it is also bioinert thus, it cannot induce bone growth. With the aim of addressing this issue, several surface modification approaches have been developed such as micro-arc oxidation (MAO) [24-34]. MAO does not only lead to a better corrosion behaviour but also can improve the bioactivity of Ti through the creation of tailored surfaces in terms of chemical composition, nano/micro porosity and topography [24-26,28-36]. Furthermore, during MAO treatment it is possible to incorporate

\footnotetext{
* Corresponding author at: CMEMS-UMinho, University of Minho, Department of Mechanical Engineering, Campus de Azurém, 4800-058 Guimarães, Portugal.

E-mail address: alexandra@dem.uminho.pt (A.C. Alves).
} 
bioactive elements, as $\mathrm{Ca}$ and/or $\mathrm{P}$, allowing to reach a $\mathrm{Ca} / \mathrm{P}$ ratio similar to hydroxyapatite (HAP) on the anodic layers. After MAO treatment, HAP may be precipitated by a hydrothermal treatment, which is reported to improve the bioactivity [28-30,37-40]. Nevertheless, the studies on the bio-functionalization of highly porous Ti surfaces by anodic treatment are still very limited [3,20,41,42]. Yavari et al. [20] studied the effect of alkali-acid heat and acid-alkali treatments on compression and fatigue behaviour of porous Ti6Al4V alloy processed by selective laser melting. The authors stated that the acid-alkali treatment leads to substantial mass loss when compared with alkaliacid heat treatment, and thus it notably modify the porous Ti6Al4V structures mechanical properties. On the other hand, Fan et al. [42] processed porous Ti scaffolds by powder metallurgy using space holder technique followed by anodic and heat treatments. The authors stated that anatase nanotubes were successfully produced on $\mathrm{Ti}$ scaffold, which improved the biocompatibility due to their apatite-formation ability.

The present study is a following work of these authors. Previous studies on bio-functionalized highly porous $\mathrm{Ti}$ showed that both outermost and inner pore surfaces were successfully covered by MAO layers leading to a lower corrosion susceptibility, both under static conditions and under sliding. The authors attributed this behaviour not only to the improved corrosion resistance provided by the MAO layers but also to the increased hardness, leading to higher wear resistance, of those layers [3]. Moreover, although no clear effect of bio-functionalization was found on cell viability, enhanced cell proliferation and activity was reported for bio-functionalized highly porous Ti having $22 \%$ of porosity [43]. Although it is well reported that MAO treatment on Ti surfaces improves the corrosion behaviour, the electrochemical response of bio-functionalised highly-porous $\mathrm{Ti}$ is yet to be known. Therefore, this study aimed at understanding the electrochemical behaviour of 3D-macro-porous architecture having bio-functionalized surfaces developed by MAO with the incorporation of Ca and P.

\section{Experimental procedure}

\subsection{Processing}

Dense Ti samples were produced using angular shaped Ti powders (Grade 2, Alfa Aesar, $\mathrm{D}_{50}=36 \mu \mathrm{m}$ ) and as a binder it was used polyvinyl alcohol (PVA, Sigma Aldrich Chemistry), for highly porous Ti samples angular shaped urea particles (Scharlau, $<500 \mu \mathrm{m}$ ) were used as a space holder.

Firstly, Ti powders and PVA ( 0.4 vol\%) were manually mixed, then 0,30 or 50 vol\% of urea was added to the mixture. In order to get a homogeneous mixture, the powders were mix in a ball mill rotating with $\mathrm{Al}_{2} \mathrm{O}_{3}$ spheres at $130 \mathrm{rpm}$ for $4 \mathrm{~h}$. The blended powders were then uniaxially pressed in a zinc stearate lubricated nitrided stainless steel die under $350 \mathrm{MPa}$ for $2 \mathrm{~min}$. The green compacts $(12 \mathrm{~mm}$ in diameter and $3 \mathrm{~mm}$ in thickness) were subjected to two thermal cycles. The first one at $450{ }^{\circ} \mathrm{C}$ during $3 \mathrm{~h}$ under $\mathrm{Ar}$ atmosphere was performed to remove the binder and the space holder. Then, the samples were sintered in vacuum (better than $10^{-5} \mathrm{mbar}$ at $1100{ }^{\circ} \mathrm{C}$ during $3 \mathrm{~h}$. The heating and cooling rates were set to $5{ }^{\circ} \mathrm{C} \mathrm{min}^{-1}$. Thermal analysis/thermal gravimetric (DTA/TG) and dilatometric tests were carried out to select the binder/space holder and sintering temperatures, this analysis is presented elsewhere [1].

\subsection{Bio-functionalization by micro-arc oxidation}

In order to achieve similar surface roughness to the highly porous samples, dense Ti samples were grounded using SiC papers with 180 mesh. Both dense and highly porous samples were ultrasonically cleaned in acetone for $3 \mathrm{~min}$ and etched in Kroll's reagent (2:10:88 in vol. of $\mathrm{HF}, \mathrm{HNO}_{3}$ and $\mathrm{H}_{2} \mathrm{O}$, respectively) for $1 \mathrm{~min}$. After the etching procedure, the samples were immediately cleaned ultrasonically in propanol for $10 \mathrm{~min}$ followed by $5 \mathrm{~min}$ in distilled water and dried with warm air.

The bio-functionalization treatment by MAO was performed in an electrolyte consisting of a mixture of $0.02 \mathrm{M}$ of $\beta$-glycerophosphate disodium salt pentahydrate, ( $\beta$-GP; Alfa Aesar) and $0.35 \mathrm{M}$ of calcium acetate monohydrate (CA; Alfa Aesar), as P and Ca ions source, respectively. Dense and highly porous Ti samples were used as anode (geometric area of $3.39 \mathrm{~cm}^{2}$ ) and completely immersed in the electrolyte, while a Pt plate was used as cathode (exposed area $12.57 \mathrm{~cm}^{2}$ ). The anode and cathode were placed $8 \mathrm{~cm}$ apart and connected to a DC power supply (GPR-30H10D). The total MAO treatment time was $1 \mathrm{~min}$ with a selected voltage of $300 \mathrm{~V}$. A magnetic stirrer rotating at $200 \mathrm{rpm}$ was used to create a turbulent flow regime. After the bio-functionalization, all samples were cleaned in an ultrasonic bath in propanol and distilled water and dried as described previously.

\subsection{Electrochemical tests}

Open circuit potential (OCP), potentiodynamic polarization and electrochemical impedance spectroscopy (EIS) tests were performed to assess the electrochemical behaviour of all groups of samples. All electrochemical tests were performed in a physiological solution consisting of $9 \mathrm{~g} / \mathrm{L}$ of $\mathrm{NaCl}$ at body temperature $\left(37 \pm 2{ }^{\circ} \mathrm{C}\right)$ as presented in Fig. 1. The electrochemical cell was placed in a climate chamber, which kept the temperature constant and acted as a Faraday cage in order to avoid any external currents. Sample surfaces were used as working electrode, a platinum wire was used as a counter electrode while a saturated calomel electrode (SCE) was used as reference electrode, connected to a Reference 600 potentiostat/galvanostat/ZRA from Gamry Instruments. All potentials are given with respect to SCE.

All samples were immersed in the electrolyte and allowed to rest for $24 \mathrm{~h}$. OCP, EIS and potentiodynamic polarization measurements were performed sequentially. OCP was continuously measured and was considered stable when $\Delta \mathrm{E}<60 \mathrm{mV} \mathrm{h}^{-1}$. Then, at $24 \mathrm{~h}$, EIS was performed at the last registered OCP with frequencies ranging from $10^{5}$ till $10^{-2} \mathrm{~Hz}$, with 7 points per frequency decade. A sinusoidal signal with an amplitude of $10 \mathrm{mV}$ was chosen in order to ensure the linearity of the electrode response. After EIS measurements, the OCP was measured during $10 \mathrm{~min}$, followed by the potentiodynamic polarization tests that started at $-0.250 \mathrm{~V}_{\mathrm{OCP}}$ and went up to $1 \mathrm{~V}_{\mathrm{SCE}}$ with a scanning rate of $1 \mathrm{mV} \mathrm{s}^{-1}$. The potentiodynamic polarization parameters were chosen in a way to determine the passivation current densities and to understand the stability of the anodic layers within the range of potentials that are reported to be relevant in human body $[44,45]$.

To guarantee the repeatability of the results, all these experiments were repeated at least three times and the results are presented as average \pm standard deviation.

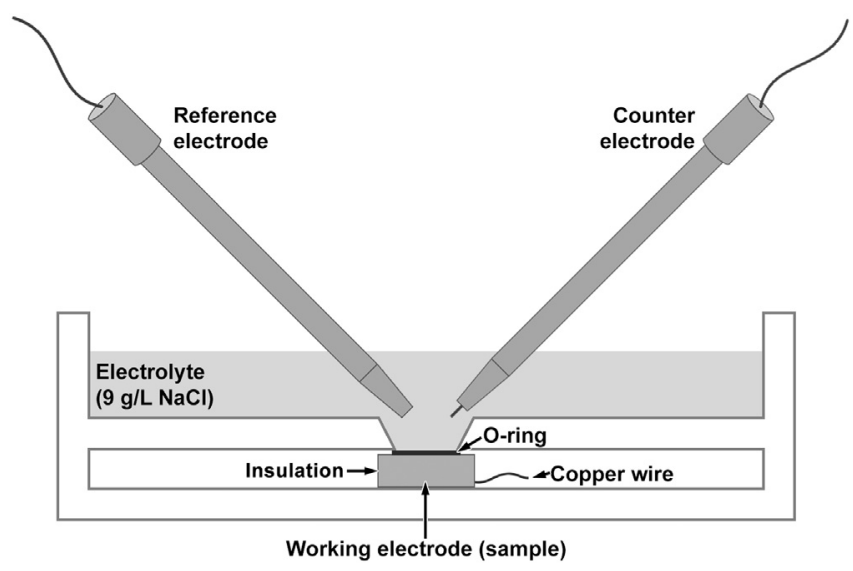

Fig. 1. Schematic representation of the electrochemical test setup. 


\subsection{Characterization}

The topography, microstructure and chemical composition of asprocessed and bio-functionalized samples were analysed by SEM using a FEI Nova 200 equipped with energy dispersive X-ray spectroscopy (EDS).

The porosity morphology and distribution of pores of highly porous Ti samples were characterized by micro-computed tomography (microCT) by using X-view X 50-CT (North Star Imaging) micro-CT system, under the accelerating voltage of $50 \mathrm{KV}$ and a tube current of $400 \mu \mathrm{A}$. For each bulk sample, 1200 projections were taken over $360^{\circ}\left(0.3^{\circ}\right.$ range) with an exposure time of $3 \mathrm{~s}$ for each projection. A CMOS image sensor ( $3888 \times 3072$ pixels) coupled to CsI scintillator was used for detecting the transmission beam. The samples were scanned with $17 \mu \mathrm{m} \times 17 \mu \mathrm{m}$ pixel size, allowing a field of view of around $3 \mathrm{~cm}$. Reconstruction was done with 2400 TIFF projections, where the average scanning time was $90 \mathrm{~min}$ per sample.

A point-counting technique based on ASTM E562 was used to calculate the number and pores size distribution of the anodic layers. This method consisted in a grid having 17 lines parallel to each other with a constant distance between them of $0.03 \mathrm{~mm}$ that was superimposed on a SEM micrograph. All the pores intersecting the lines were counted and their diameters were measured. From each group of bio-functionalized samples, three SEM micrographs were taken in different zones of the surface's samples and five samples were used per group of samples. The groups of sample are presented in Table 1 together with the nominal porosity, real porosity and surface treatment.

The cross-section of the anodic layers was analysed using a FIB-SEM (Auriga Compact, ZEISS). Gallium ions at $30 \mathrm{keV}$ were used to section the surface, with a $5 \mathrm{nA}$ current up to a depth of approximately $20 \mu \mathrm{m}$, and to clean the edge of the cross-section, with $1 \mathrm{nA}$ currents.

The real exposed metallic area to the electrolyte for highly porous samples was determined from the voxelized true geometry of the porous sample derived from the raw data acquired by micro-CT. After the 3D reconstruction, gray-scale data of the voxels was submitted to the following procedure: i) denoising by a Gaussian technique; ii) segmentation of the full 3D domain between (0) world (outside domain), (1) matrix (Ti) and (2) void (pores), based on a simple threshold technique, with the threshold value determined from the histogram of images from the material + voids domain. After segmentation and being known the 3D geometry of the porous sample, an arbitrary flat surface was selected; following the experimental procedure, the free subsurface area delimited by the o-ring is numerically flooded, as well as all void voxels in contact with the flooded region. By the end, the area of the interface between the void flooded region and the matrix was simply integrated by counting the number of elementary surfaces (voxel faces) of the flooded region/matrix interface.

\section{Results}

\subsection{As-processed surfaces}

Previous results [1] had shown that, for the same processing

Table 1

Samples groups with their nominal porosity, real porosity, and surface treatment.

\begin{tabular}{llll}
\hline Group & $\begin{array}{l}\text { Nominal porosity (as urea \% } \\
\text { vol) }\end{array}$ & $\begin{array}{l}\text { Real porosity (\%) } \\
{[1]}\end{array}$ & Surface treatment \\
\hline Ti & - & 0.4 & Etched \\
Ti22 & 30 & 22 & Etched \\
Ti37 & 50 & 37 & Etched \\
Ti-AT & - & 0.4 & Bio-functionalized \\
Ti22-AT & 30 & 22 & Bio-functionalized \\
Ti37-AT & 50 & 37 & Bio-functionalized \\
\hline
\end{tabular}

conditions, approximately $80 \%$ of the pores in both highly porous $\mathrm{Ti}$ samples ranged from 50 to $350 \mu \mathrm{m}$. Although Ti22 group presented an average pore size of $230 \mu \mathrm{m}$, the average pore size of Ti37 samples was slightly lower, around $200 \mu \mathrm{m}$. Microstructural and 3D tomographic investigations revealed that Ti22 samples mainly presented closed pores, while Ti37 samples showed a mixture of open (interconnected) and closed pores. Considering its importance on the electrochemical tests, the real metallic area exposed to the electrolyte was calculated using the micro-CT data. For a geometric area of $0.38 \mathrm{~cm}^{2}$ the real metallic area exposed to electrolyte was $1.18 \mathrm{~cm}^{2}$ and $14.8 \mathrm{~cm}^{2}$ for Ti22 and Ti37, respectively. It was observed on the 3D reconstructions that the flooded region did not pass completely through the sample on Ti22. However, since Ti37 samples contained a mixture of open and closed pores, whatever the first flat surface selected on 3D reconstructions, the flooded region always crossed completely the sample, meaning that the upper and lower surfaces were always linked by the void region (Fig. 2). Thus, these calculated real exposed areas were used to normalize the electrochemical data.

\subsection{Current density evolution with anodic treatment time}

The current density evolution during the MAO treatment at $300 \mathrm{~V}$ is given in Fig. 3. All curves showed two different regions: In region I, the current was constant (limiting current of $2.6 \mathrm{~A}$, which was the maximum current provided by the power supply) until the system reached the selected potential $(300 \mathrm{~V})$. When $300 \mathrm{~V}$ was reached (moment indicated as $t_{\text {gal } / p o t}$ ), the anodic treatment turned to constant voltage control and a decrease on current values was observed (region II), thus, the formation of micro-arcs and evolution of gas in the system started [34]. Moreover, it was observed that the density of micro-arcs decreased while the current fell. The parameter $t_{\text {gal/pot }}$ corresponds to the time at which the final potential is reached, being $13 \pm 1,23 \pm 1$ and $48 \pm 1 \mathrm{~s}$ for Ti, Ti22 and Ti37, respectively. Higher levels of porosity led $t_{\mathrm{gal} / \mathrm{pot}}$ to increase probably due to the increased exposed metallic area. However, the current density is not significantly different for all group of samples.

\subsection{As-etched and bio-functionalized surfaces}

Fig. 4 presents the SEM micrograph of as-etched and bio-functionalized surfaces. As previously reported by some of the present authors $[1,3]$, along with the induced porosity, residual porosity was presented in all etched surfaces (Fig. 4b and c), being typical on the conventional powder metallurgy processing method. On the other hand, as already reported by some of the present authors [1], the difference between the nominal porosity (30 and 50\%) and the measured porosity (22 and $37 \%$, respectively) is attributed to shrinkage, which increased as the amount of the space holder was increased. The grinding marks on the as-etched Ti surfaces (Fig. 4a) were still visible after etching. However, after anodic treatment, those grinding marks were not disappeared (Fig. 4d) and a multiscale porous structure was obtained. It has also been previously reported that after anodic treatment the surface roughness had increased from 0.63 to $1.27 \mu \mathrm{m}$ [3]. The volcano-like porous structure, typical of micro-arc treated surfaces, was observed in all samples. Moreover, in the case of Ti22-AT and Ti37-AT (Figs. 4e-f), the uppermost pore surfaces were successfully covered by the anodic layers formed during the bio-functionalization process. The size of the pores of the anodic layers ranged from approximately 0.6 to $2.9 \mu \mathrm{m}$, in accordance with the values reported in the literature [34,35].

The ratio of $\mathrm{Ca} / \mathrm{P}$ (\% weight), based on EDS analysis, is $3.44 \pm 0.15,3.38 \pm 0.23$, and $3.46 \pm 0.40$ for Ti-AT, Ti22-AT, and Ti37-AT respectively. Moreover, the crystalline structure of the anodic layers processed under identical conditions was previously characterized as a mixture of anatase and rutile [3].

In this study, Ti-AT samples presented the largest pores size distribution, ranging from 0.60 to $3.68 \mu \mathrm{m}$, while for porous bio- 


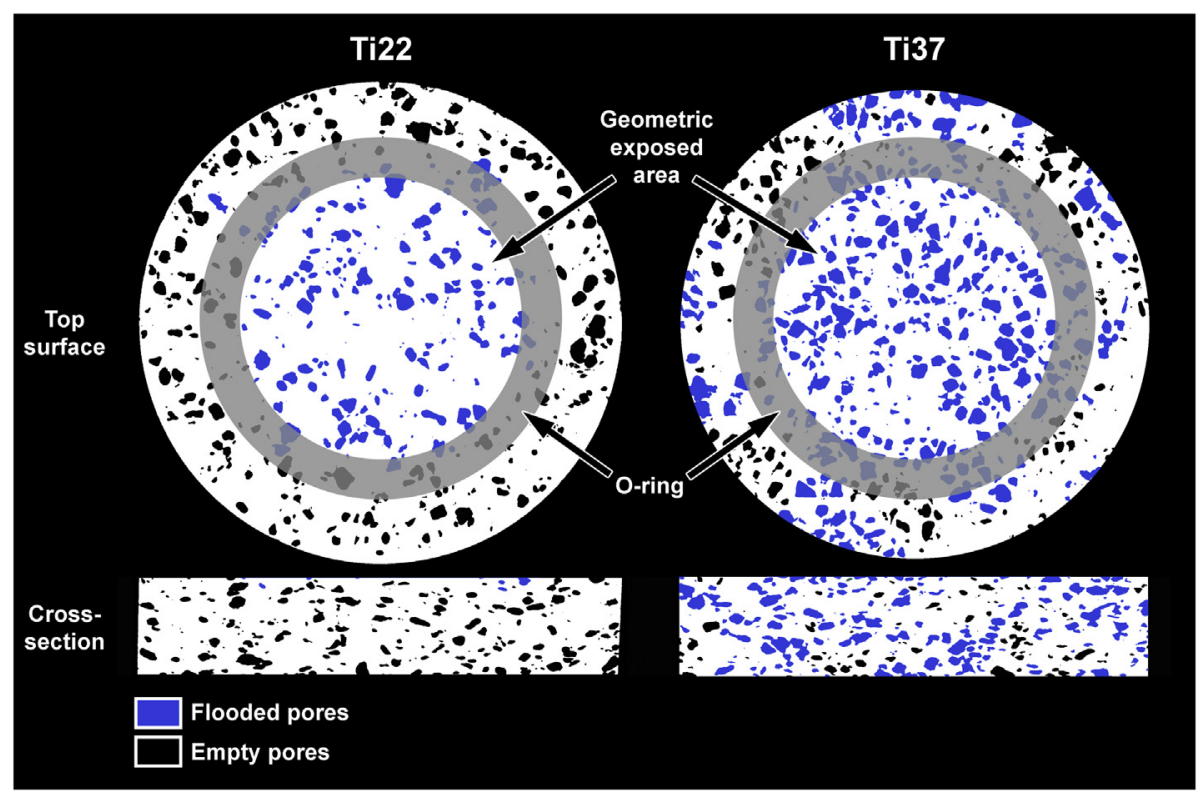

Fig. 2. Surface and cross-section tomographic slice images showing the exposed geometric area for the electrochemical tests, and the simulation of flooded pores by electrolyte.

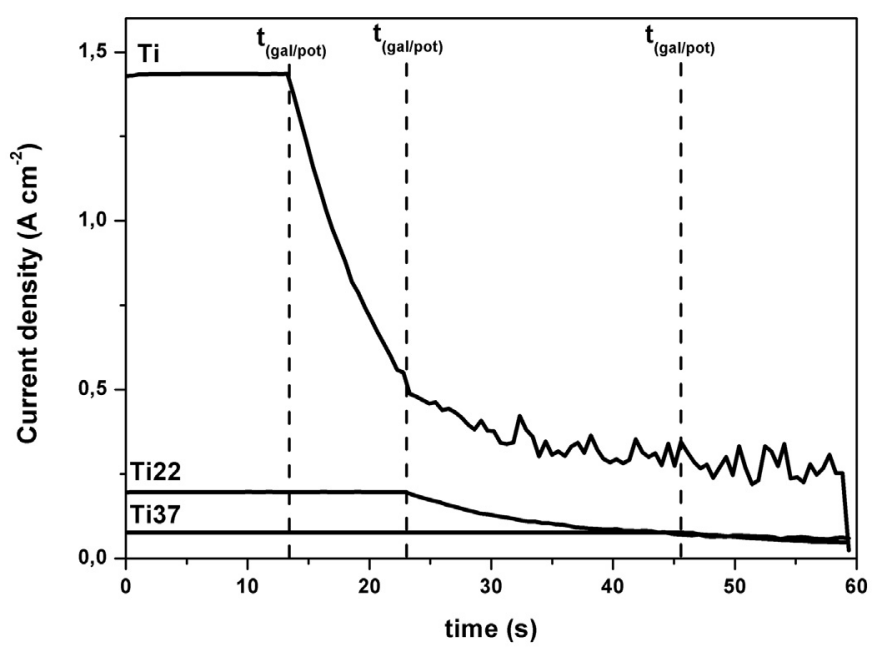

Fig. 3. Current density evolution during the anodic treatment at $300 \mathrm{~V}$.

functionalized samples it ranged from 0.24 to 2.91 and from 0.21 to $2.58 \mu \mathrm{m}$ for Ti22-AT and Ti37-AT, respectively (Fig. 5). Most of the pores on Ti-AT had a diameter between 1.0 and $1.5 \mu \mathrm{m}$. In the case of Ti22-AT and Ti37-AT, the pore sizes decreased, with diameters between 0.5 and $1.0 \mu \mathrm{m}$. Also, the number of pores per geometric surface area was different comparing Ti-AT and Ti22-AT/Ti37-AT groups, namely $(9.2 \pm 2.3) \times 10^{3}$ pores $\mathrm{mm}^{-2}$ for Ti-AT and $(11.7 \pm 1.6) \times 10^{3}$ and $(11.9 \pm 1.7) \times 10^{3}$ pores $\mathrm{mm}^{-2}$ for Ti22-AT and Ti37-AT, respectively. Thus, within the bio-functionalized samples, there was a slight increase on the number of pores from dense to porous samples. However, no significant differences were observed between Ti22-AT and Ti37-AT.

Representative SEM micrographs of FIB-prepared cross-sections of the anodic layers formed on the outermost surfaces are presented in Fig. 6. The anodic layer formed in both dense and highly porous Ti samples presented a triplex structure, where no significant differences were observed, at least on the outermost surface. The barrier film is formed at metal/oxide interface in the first seconds of the anodic treatment. This barrier film is followed by two porous layers, an inner porous layer that is characterized by small pores, and an outer porous layer that presents larger pores [35]. All anodic layers with the triplex structure presented an average overall thickness of approximately $2.50 \mu \mathrm{m}$. However, in the most inner pores, the formed anodic layer may present some heterogeneities, most probably due to the difficulty of the electrolyte to wet all the exposed metallic area in the case of highly porous samples.

\subsection{Electrochemical behaviour}

OCP, EIS and potentiodynamic polarization measurements were performed sequentially. After the immersion of each sample, the evolution of its OCP was monitored for $24 \mathrm{~h}$ and a stable condition was assumed when the potential drift became lower than $60 \mathrm{mV} \cdot \mathrm{h}^{-1}$. The OCP values recorded during the last hour of monitoring, just before the EIS measurement, are presented in Fig. 7. It was observed on the asetched samples that increased porosity led to a decrease on the corrosion susceptibility by presenting values of OCP less negative for the highest level of porosity (Ti37). On the other hand, the bio-functionalized samples presented nobler values than as-etched samples, showing a lower tendency to corrosion, although this difference samples was not significant on Ti37.

Fig. 8 shows the representative potentiodynamic polarization curves of as-etched and bio-functionalized samples and Table 2 presents the average OCP (average of the last $10 \mathrm{~min}$ of monitoring), corrosion potential $\left(\mathrm{E}_{\text {corr }}\right)$ and passivation current density $\left(i_{\text {pass }}\right)$ taken as the respective current density at $0.4 \mathrm{~V}_{\mathrm{SCE}}$. As-etched Ti showed the lowest corrosion potential and a well-defined passivation plateau starting at approximately $0.1 \mathrm{~V}_{\mathrm{SCE}}$. The $\mathrm{E}_{\text {corr }}$ showed a clear improvement from $\mathrm{Ti}$ to Ti-AT samples. Bio-functionalized Ti showed a passivation plateau starting from $c a-0.1 \mathrm{~V}_{\mathrm{SCE}}$ to $0.39 \mathrm{~V}_{\mathrm{SCE}}$, followed by a slight increase of the current, which may be related to the dissolution of calcium and phosphorous on the MAO layer. The passivation current density showed a decrease of almost two orders of magnitude from Ti to Ti-AT samples. As-etched highly porous $\mathrm{Ti}$ samples presented $\mathrm{E}_{\text {corr }}$ slightly nobler than Ti. Even though no well-defined passivation plateau was recorded, these groups of samples presented a passivation region, where a slow increase of the current density rate on the anodic domain around $10^{-5}$ $\mathrm{A} \mathrm{cm}^{-2}$ was observed.

Fig. 9 shows the electrochemical impedance spectra for as-etched and bio-functionalized samples in the forms of Bode (Fig. 9a-c) and 

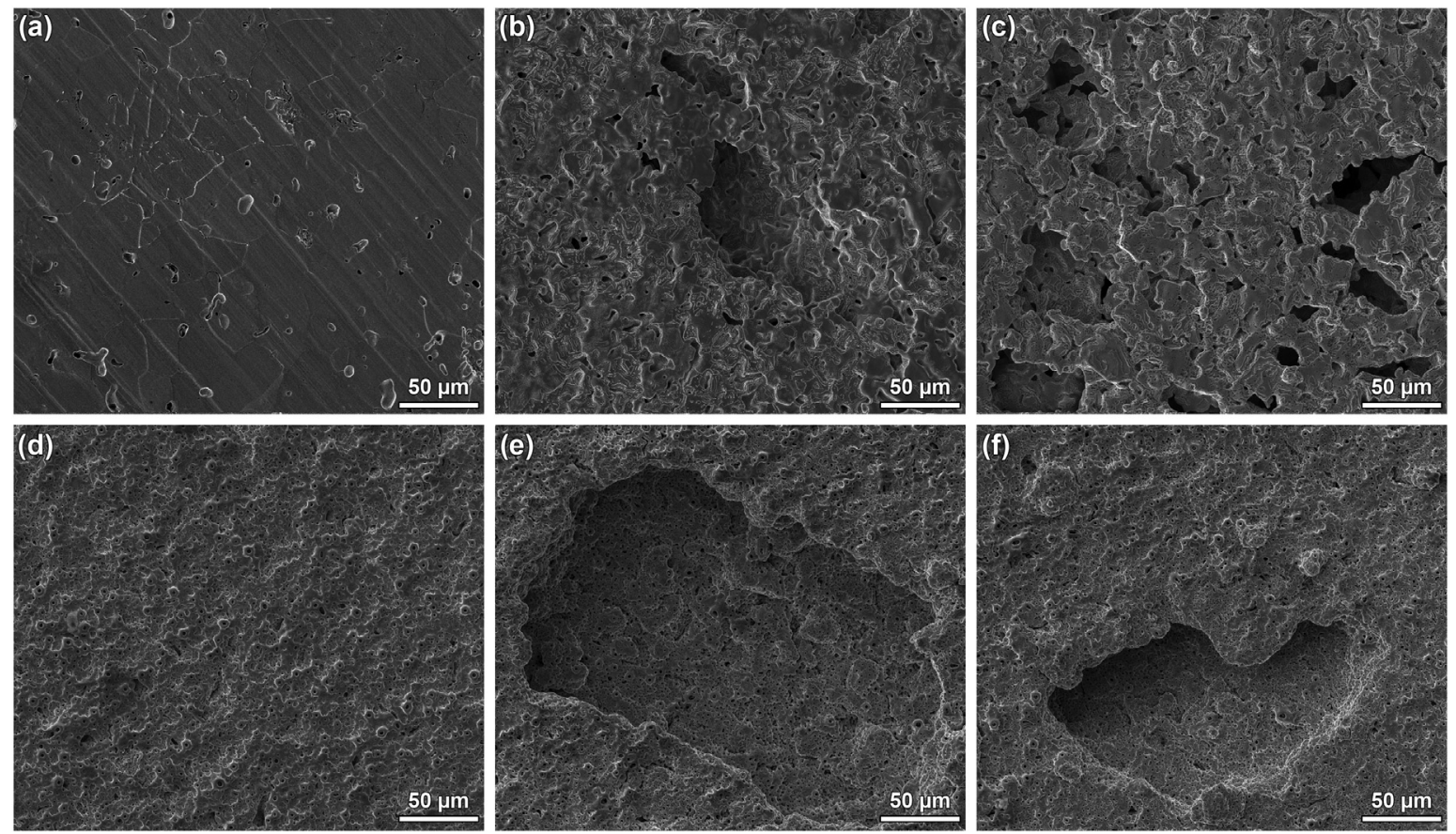

Fig. 4. Secondary electron SEM images of the as-etched (a-c) and bio-functionalized (d-f) Ti, Ti22, and Ti37 samples, respectively.

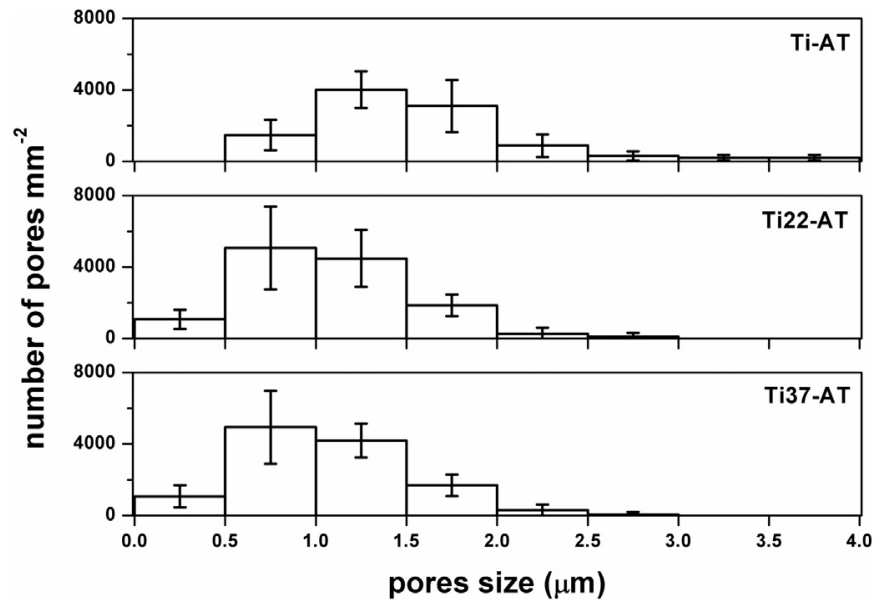

Fig. 5. Pores size distribution on the bio-functionalized samples.

Nyquist (Fig. 9d-f) diagrams, respectively. Comparing the Nyquist diagrams, an increase can be observed on the diameter of the semicircle from as-etched to bio-functionalized samples. This behaviour suggests a better corrosion resistance of bio-functionalized samples. Constant values of $|\mathrm{Z}|$ and phase angles close to $0^{\circ}$ were obtained in the Bode diagrams for all as-etched samples at the high frequencies range, being the typical response of the electrolyte resistance. Independently of the porosity level, just one time constant was observed. In low and middle frequency range, the typical capacitive behaviour of a compact oxide film was observed by the phase angle values approaching $-90^{\circ}$ for Ti. Regarding Ti22 and Ti37, the phase angle approached to $-70^{\circ}$ and $-50^{\circ}$, respectively. This is an effect of the decrease of exponent $n_{o x}$ of the CPE, in agreement with the higher heterogeneity of an increasingly porous material.

Concerning the bio-functionalized samples, all groups presented three time constants; two corresponding to middle-high frequencies, where the phase angle approached to $-40^{\circ},-30^{\circ}$, and $-20^{\circ}$ for Ti-AT, Ti22-AT, and Ti37-AT, respectively, and a third one (low frequencies), characterized by an increase of the phase angle $\left(-80^{\circ}\right.$ and $-60^{\circ}$ for Ti-
AT and Ti22-AT, respectively) with the exception of Ti37-AT, where no significant difference was observed on the phase angle from high to low frequencies, due to the larger values of the electrolyte resistance.

Fig. 10a gives the schematic representation of the electrical equivalent circuit (EEC) used for fitting the EIS results of as-etched samples. An $R_{e}\left(R_{o x} Q_{o x}\right)$ circuit was used to represent the native oxide film formed on exposed sample surfaces, where $R_{e}$ is the electrolyte resistance, $R_{o x}$ is the native oxide film resistance and $Q_{o x}$ is a constant phase element (CPE), considering a non-ideal capacitance of the native oxide film. The schematic representation of the EEC used for fitting the EIS results of bio-functionalized samples is presented in Fig. 9b. The presented EEC was recently proposed by some of the present authors to fit EIS results for commercial pure Ti, bio-functionalized by MAO under conditions similar to those used in the present study [35]. In this EEC, the barrier film is represented by a resistor $R_{b f}$ and a constant phase element $\mathrm{Q}_{\mathrm{bf}}$. Regarding the porous layers, the intact porous wall (outer porous layer, Figs. 6 and 10) and the porous wall under the outer pores (inner porous layer, Figs. 6 and 10) are represented by $Q_{\text {wall }}$ and $Q_{1}$, 2wall, respectively. No resistor was considered in parallel with these CPEs as the thickness of the corresponding layers was too high, leading to a very high resistance, as electronic conduction is almost impossible. Moreover, the overall electrolyte resistance was represented by $R_{e}$, together with the additional resistances of the electrolyte inside the outer pores $\left(\mathrm{R}_{\mathrm{e}^{\prime}}\right)$ and inner pores $\left(\mathrm{R}_{\mathrm{e}^{\prime \prime}}\right)$.

In order to allow the representation of a non-ideal capacitor, a CPE was used in the fitting. The impedance of CPE is defined as: $Z_{C P E}=\left[Y_{0}(j \omega)^{n}\right]^{-1}$, where $-1 \leq n \leq 1$. For $n=1, n=0$, or $n=-1$ the CPE response corresponds to a capacitor, a resistor or an inductor, respectively. A non-ideal capacitor may be described by a CPE if $n \sim 1$. However, it is known that the surface roughness and its heterogeneities influence the $n$ values. All as-etched samples presented $n$ values higher than 0.90 in the case of dense Ti, while for porous samples the $n$ values were always higher than 0.74 . Regarding the bio-functionalized samples, the lowest $n$ was 0.71 . All the impedance spectra were fitted to these circuits using Zview software (version 2.9) and the quality of the fittings was evaluated by their chi-square values. All as-etched samples presented chi-square below $10^{-4}$ and in the case of the bio-functionalized samples the chi-square was below $10^{-3}$. The EEC parameters 

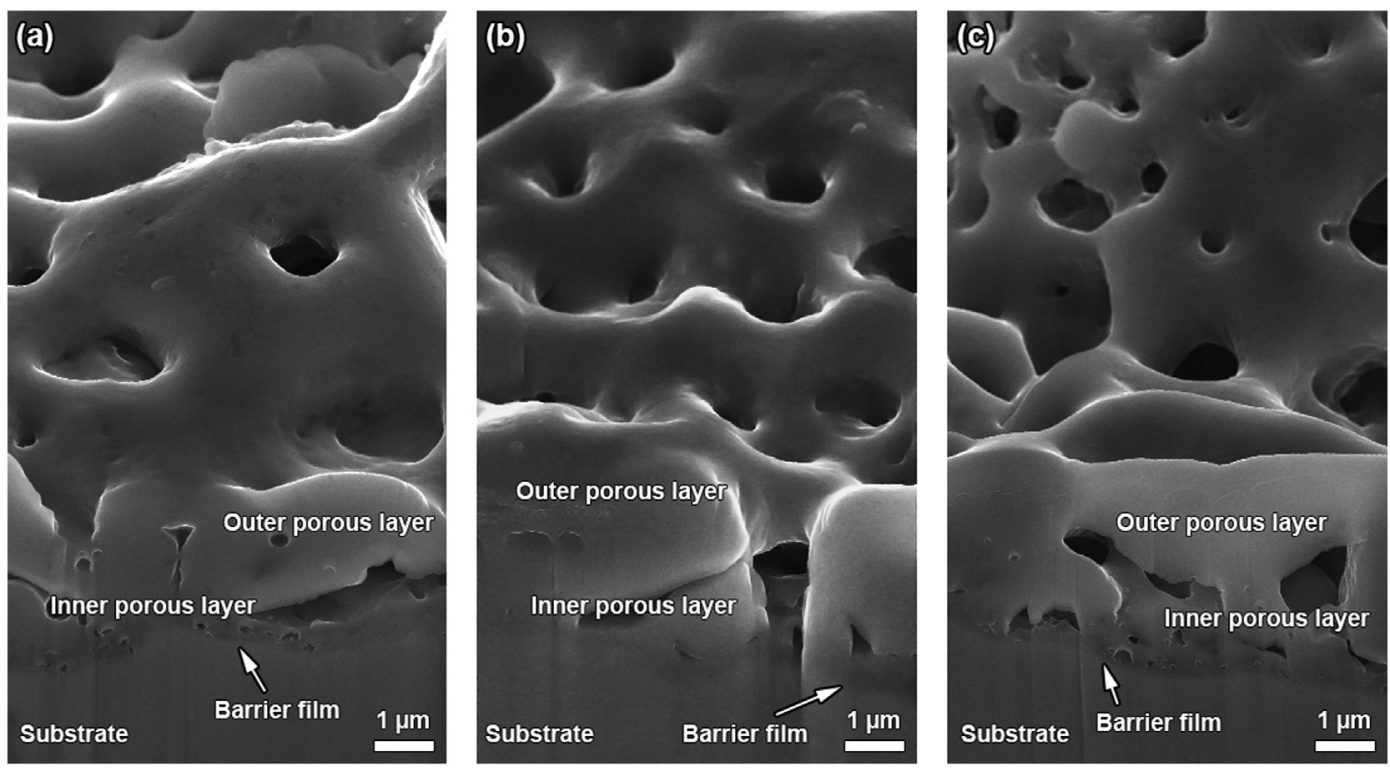

Fig. 6. SE SEM images of FIB-prepared cross-sections of the anodic layers for: a) Ti-AT, b) Ti22-AT, and c) Ti37-AT samples.

obtained from EIS data for as-etched and bio-functionalized samples are presented in Table 3.

\section{Discussion}

\subsection{Bio-functionalization}

MAO treatment has two distinct stages. In the first stage, anodic layer formation proceeds as the conventional anodic treatment mechanism where a compact and thin oxide film is formed. Then, when the dielectric breakdown potential is reached, oxide phases such as anatase and rutile are formed as a result of the extremely high temperatures that are locally reached at the metal/electrolyte interface due to the micro-arcs that occur at that interface [46]. Moreover, the transformation of metastable anatase to stable rutile is facilitated by the frequent micro-discharges. On the other hand, the formed oxides present low thermal conductivity, which increases the local temperature, thus further transformation of anatase to rutile is also promoted, as reported by Wang et al. [47]. However, some studies [32,35] show that decreased electrolyte conductivity may increase the amount of rutile phase. Although increased macro-porosity level led to an increase on the galvanostatic control, no differences were observed on the anatase/ rutile ratio. During the galvanostatic control, the highest current was reached and kept constant until the selected voltage was reached. However, the remaining sparks were probably more energetic than the previous ones and therefore, the transformation of anatase to rutile occurred.

By increasing the duration of galvanostatic control (i.e. for longer $t_{\mathrm{gal} / \mathrm{pot}}$ ), it is considered that the thickness of the barrier film (thin and compact oxide film) increased, as shown by the decrease of $Q_{b f}$ values (Table 3) from Ti-AT to Ti22-AT and Ti37-AT. In theory, longer galvanostatic regions lead to an increase on the total charge of the system $(\mathrm{Q}=\mathrm{I} \times \mathrm{t})$, which would influence the amount of oxide formed during this stage of the process. On the other hand, on the second stage (when currents fall), higher currents are usually associated to thinner oxide films [32]. However, the increase of total charge did not account for a significant difference in the thickness of the MAO layer (at least on the outermost surface, Fig. 5). Also, from the cross sections obtained for the samples from each group, it was not possible to observe any visible effects in the compactness of the oxide. On the other hand, micro-pores were formed at high voltages (exceeding the electrochemical breakdown potential) and the species present in the electrolyte were incorporated into the porous oxide layer [27-31,38]. Consequently, MAO process resulted in porous surfaces with a wide range of pore sizes $[33,37]$ presenting the well-known volcano-like structures. Furthermore, it is known that using a mixture of CA and $\beta$-GP as electrolyte in MAO leads to incorporation of elements as $\mathrm{Ca}$ and $\mathrm{P}$ in the porous oxide layers, being one advantage of the MAO treatment since the presence of bioactive elements as $\mathrm{Ca}$ and $\mathrm{P}$ may improve the bioactivity of $\mathrm{Ti}$ [24-31,38,39].

\subsection{Electrochemical behaviour}

Results showed that porosity affected the corrosion behaviour of highly porous Ti samples where increased $i_{\text {corr }}$ values were observed for Ti22 and Ti37 samples, in accordance with the literature [1,48-50]. Some of the present authors [1] have previously explained these differences by the effect of porosity on the formation rate of the passive oxide layer. Moreover, several authors working on the corrosion behaviour of porous metallic materials have stated the difficulties on calculating the real metallic area exposed to the electrolyte solution [51-56]. In the present work, a model has been used for the accurate calculation of the real metallic exposed area. However, this model does not consider the oxygen/air entrapped in the most inner pores neither the difficulty of electrolyte penetration into these pores, which may lead to different passive states on the native oxide film. Nevertheless, the corrosion rate of highly porous structures is not just influenced by the surface area. Although Ti is known for its high resistance to localized corrosion, and the localized breakdown of its passive film occurs at relatively higher potentials [57], the effect of the highly porous architecture on localized corrosion is yet to be fully understood. Some authors [51-54] stated that the increased corrosion density with the increased porosity level is due to the larger surface area in contact with the electrolyte, but crevices or restrictions to the flow of species into the interconnected pores can result in corrosion rates that are not proportional to the real contact surface area. In this respect, Blackwood et al. [54] stated that the attempts to accurately assess the true effective surface area directly wetted by the electrolyte are not enough to understand the corrosion behaviour of the highly porous metallic structures, since they do not take into account the restrictions on the flow of species. Although these difficulties may result in increased corrosion kinetics, excellent passivation characteristics are still reported in the literature for porous Ti structures [51-53,56]. On the other hand, Seah et al. [51] also reported decreased corrosion susceptibility (less 

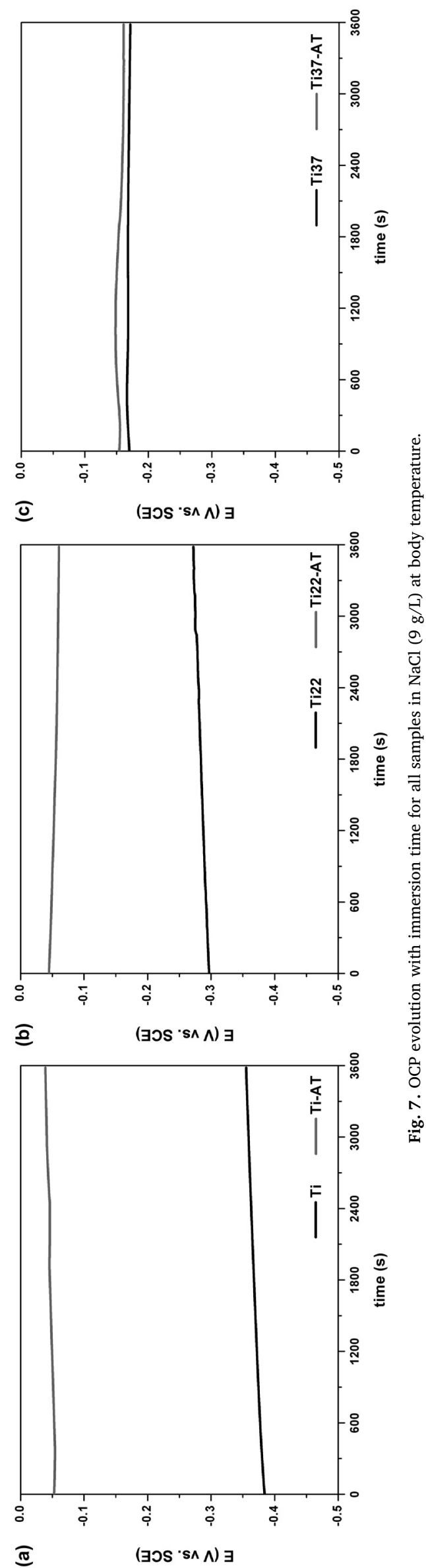

negative values of $\mathrm{E}_{\text {corr }}$ ) with increasing amount of porosity, since the interconnected pores promoted the free flow of ionic species, whereas isolated pores trapped the electrolyte and exhausted the oxygen supply, resulting in a thinner oxide film. Apart from electrolyte penetration, entrapped air, and free flow of species, as Damborenea et al. [44] reported for the Ti6Al4V scaffolds by direct metal laser sintering (DMLS), the three-dimensional architecture of the scaffolds might also have an influence on their corrosion behaviour, due to the presence of edges and vertices in the samples that may lead to different corrosion response when compared with flat surfaces.

The decreased values on $|\mathrm{Z}|$ and phase angle from Ti to Ti22 and Ti37 were probably due to the difference in the nature of the passive film. Recently, some of the present authors [1] reported two time constants for porous $\mathrm{Ti}$ samples: the first on middle frequencies representing the response of the most external pores, and the second time constant on the low frequencies characterizing the inner pores. Due to their complex geometry, the most inner surfaces may lead to a slower and more difficult penetration of the electrolyte. In the referred study [1], the authors used a conventional three-electrode electrochemical cell (adapted from ASTM: G3-89), where the samples were placed vertically. In order to overcome the difficulty of removal of entrapped oxygen, which limits the electrolyte penetration into the inner pores, and to facilitate the formation of a more homogeneous passive film, the testing set-up was changed, and the samples were placed horizontally, as shown in Fig. 1. The average values of the native oxide film capacitance were increased from Ti to Ti22 samples, but no relevant differences were found between Ti and Ti37 samples. On the other hand, $R_{\text {ox }}$ values decreased with increased porosity, independently of the porosity level. These results showed that although a passive film was formed on Ti surfaces and inside pores, it presented different corrosion resistance. In principle, this behaviour would be assigned to a deterioration of the protective nature of the oxide film, but in the present case it is important to stress that a huge increase in the surface area occurred in the porous materials leading to different passive states at the surface and inside the pores, as evidenced by the differences on the phase angles for the highly porous samples (Fig. 9).

Research on porous materials is not new and, in particular, there has been previous research published on the general topic of porosity and about its effect on the electrochemical results [1,22,23]. This work departs from previously existing knowledge and tries to obtain a deeper insight on the behaviour of these materials. Impedance results for complex systems may be difficult to interpret just based on the visual analysis of Nyquist or Bode spectra. This has led to a large number of analysis strategies whose discussion was not intended in this manuscript and that may include the use of special-purpose graphics or the modification of the data. As an example, the methodology, recently proposed by Tribollet [58], where the Bode plots were obtained after subtracting the ohmic impedance, leads to a complete modification of the phase plot at high frequencies, revealing processes (and corresponding time constants) that might be hidden in the original spectrum. This has happened in the present work with the as-etched samples, where a fine analysis has shown that, instead of the proposed one time constant equivalent circuit, a ladder model with two time constants could be more appropriated to account for the effect of porosity. However, this effect was so subtle that the corresponding time constant was not evident in the spectrum and, for the sake of simplicity in the analysis, the one-time constant circuit was maintained. On the other hand, the evolution of the parameters of a three or four time constant system may not reflect easily on the corresponding spectra. Thus, just a discussion of the effects of porosity on the Bode plots is not straightforward. Moreover, several degenerated equivalent circuits may be used for three time constants, resulting in similar spectra, even if they have no physical meaning. Thus, for the choice of an equivalent circuit, there is a need for more information than that exclusively provided by the impedance spectra, in particular that originating from the morphology and structure of the system. Therefore, in the present work it is 
(a)

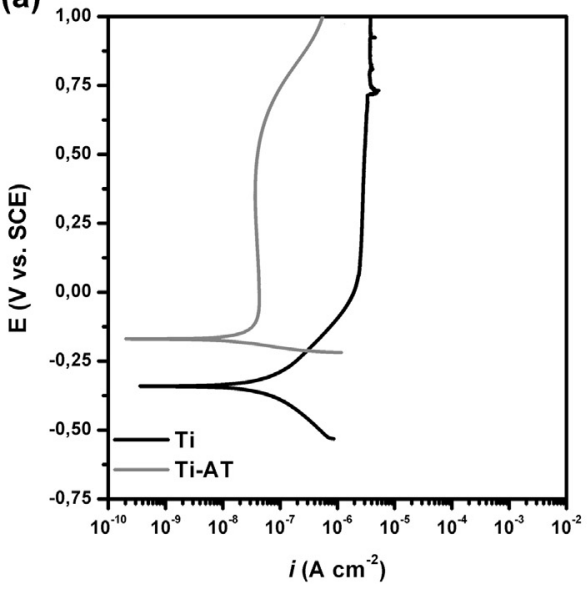

(b)

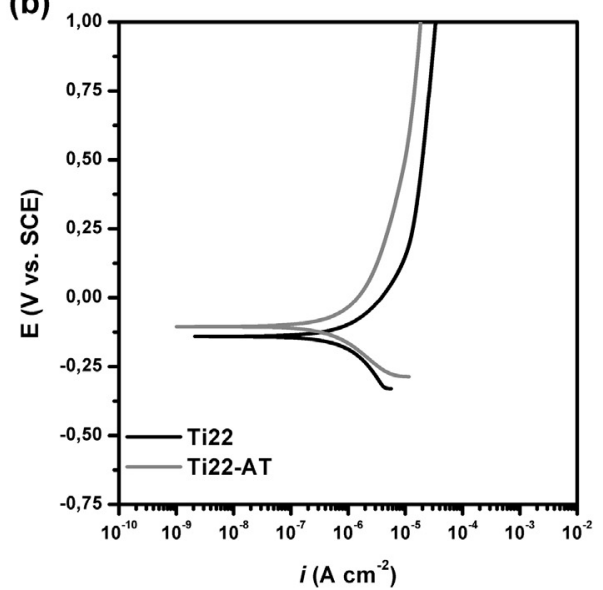

(c)

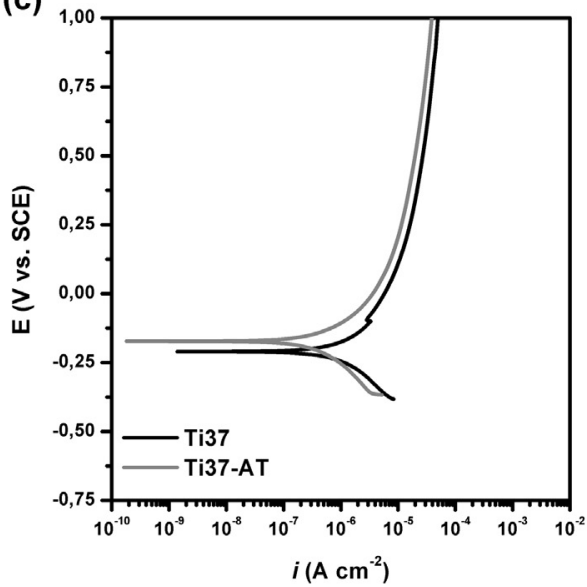

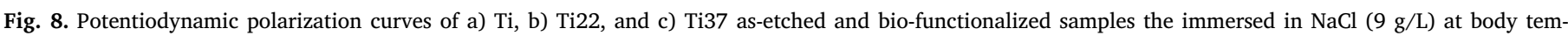
perature.

not easy to establish a cause-effect relationship between the analysis of the spectra and the choice of the proposed equivalent circuits. The strategy is then to propose a circuit that leads to an appropriate fitting of the results, with meaningful parameters, in the expected orders of magnitude, and that, by establishing the correspondence of each circuit element with a physical process, may explain the behaviour of the sample.

It is very well reported in the literature that MAO treatment improves the corrosion behaviour of $\mathrm{Ti}$, along with bioactivity [29,31-34,37,59]. In the present study, a clear improvement was observed on the dense $\mathrm{Ti}$, whereas the improvement was relatively limited on the highly porous samples. This behaviour may be explained by the complexity of the system, having a highly porous structure including interconnected pores. It is acceptable to assume that the most inner pores might not be reached by the electrolyte during the anodic treatment [3]. Consequently, the most inner pores might not be uniformly covered by the typical anodic layers. Even though, a slight improvement was obtained on the porous samples after bio-functionalization, namely on the corrosion potential and corrosion current density.

The lowest $\mathrm{Q}_{\mathrm{bf}}$ values were found for Ti37-AT samples, while a slight increase from Ti-AT to Ti22-AT samples was observed (Table 3). This behaviour may be explained by the increased galvanostatic conditions where the barrier film was formed. Ikonopisov [60] stated that the breakdown voltage is practically independent of the current density. Recently, Mathis et al. [46] showed that, under galvanostatic conditions, micro-arc initiation voltages observed were similar to the ones obtained during potentiodynamic scans. The authors also suggested three stages of galvanostatic conditions: $i$. the formation of an inner barrier inner layer leading to a sharp increase of voltage with time; ii. increase of the voltage and formation of first micro-arcs; and finally, iii. the stabilization of the voltage and transformation of the micro-arcs into large energetic arcs. Thus, the lower values of $\mathrm{Q}_{\mathrm{bf}}$ for Ti37-AT were probably due to the increased $t_{\text {gal/pot }}$ giving longer time for barrier film formation. Moreover, due to the complexity of the porous sample geometry, the $Q$ values might be affected as the surface area significantly increased with increased porosity. Nevertheless, the $\mathrm{Q}_{\text {wall }}$ values were always lower when compared with $\mathrm{Q}_{1 / 2 \text { wall, }}$, which may result from the lower thickness of the oxide corresponding to $Q_{1}$ / 2wall. Assuming a parallel plate capacitor, the dependence of the capacitance with thickness is given as $C=\varepsilon \varepsilon_{0} A / d$, where $\varepsilon$ is the dielectric constant, $\varepsilon_{o}$ the vacuum permittivity, $A$ is the surface area and $d$ is the thickness, so a thinner layer will lead to higher capacitances. Furthermore, no relevant differences were found for $Q_{\text {wall }}$ values with increased porosity, showing the ability to form the anodic layers on the outermost porous surfaces. However, an increase on $\mathrm{Q}_{1 / 2 \text { wall }}$ values was found for bio-functionalized porous samples, probably due to the fact that the anodic layer might not be homogenously formed on the most inner pores. When the $\mathrm{Q}_{\mathrm{bf}}$ of the bio-functionalized samples was compared with the as-etched $Q_{o x}$ values, it was noticed that the $Q_{b f}$ values were always lower than $\mathrm{Q}_{\mathrm{ox}}$, showing the improvement in the corrosion behaviour by the anodic treatment.

Although the anodic layers formed on the outermost surfaces did not exhibit significant differences between dense and highly porous $\mathrm{Ti}$ (Fig. 6), there is still a lack of knowledge on the structure of the inner pores, where the anodic layer may not be fully formed. Anyway, the present values seem to be easily explained considering the above factors. Nevertheless, to get a deeper understanding on the electrochemical behaviour of bio-functionalized highly porous Ti, long-time immersion tests involving OCP monitoring and periodic EIS measurements in physiological solution should be performed on samples having more levels of macro-porosity, together with potentiodynamic tests after different immersion times. On the other hand, there is a need to understand the morphology, composition and homogeneity of the anodic layers formed on the most inner pores, as a function of macroporosity.

\section{Conclusions}

The effect of macro-porosity on the composition, structure and electrochemical behaviour of the bio-functionalized highly porous $\mathrm{Ti}$ was studied. Within the limitations of this work, it is concluded that the presence of macro-porosity did not deteriorate the bio-functionalization treatment, on which regards chemical composition $(\mathrm{Ca} / \mathrm{P}$ ratio) and layer structure. The electrochemical behaviour of highly porous

Table 2

Open circuit potential, corrosion potential $\mathrm{E}_{\text {corr }}$, and passivation current density $\left(i_{\text {pass }}\right)$ values for all groups of samples.

\begin{tabular}{|c|c|c|c|c|c|c|}
\hline & $\mathrm{Ti}$ & Ti-AT & Ti22 & Ti22-AT & Ti37 & Ti37-AT \\
\hline $\mathrm{E}_{\mathrm{OCP}}\left(\mathrm{mV}_{\mathrm{SCE}}\right)$ & $-354 \pm 9$ & $-32 \pm 22$ & $-174 \pm 90$ & $-82 \pm 57$ & $-157 \pm 34$ & $-136 \pm 30$ \\
\hline $\mathrm{E}_{\text {corr }}\left(\mathrm{mV}_{\mathrm{SCE}}\right)$ & $-356 \pm 12$ & $-152 \pm 41$ & $-170 \pm 96$ & $-109 \pm 29$ & $-186 \pm 40$ & $-196 \pm 36$ \\
\hline$i_{\text {pass }}\left(\mu \mathrm{Acm}{ }^{-2}\right)$ & $3.24 \pm 0.95$ & $0.05 \pm 0.02$ & $13.33 \pm 3.62$ & $5.89 \pm 1.72$ & $26.50 \pm 5.05$ & $17.97 \pm 1.90$ \\
\hline
\end{tabular}


(a)

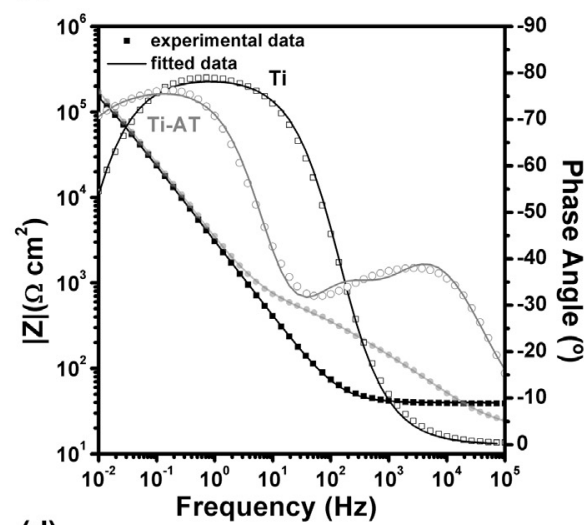

(d)

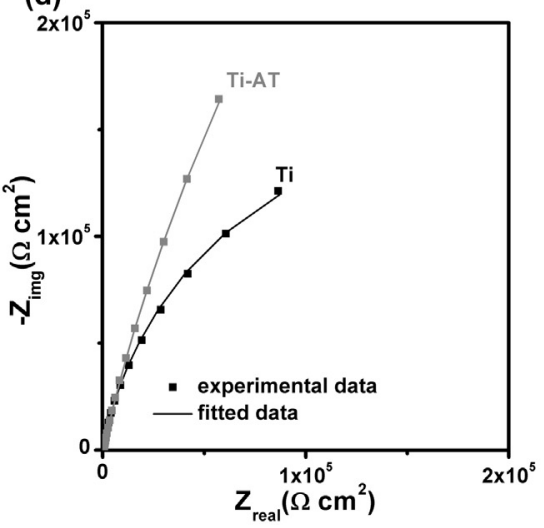

(b)

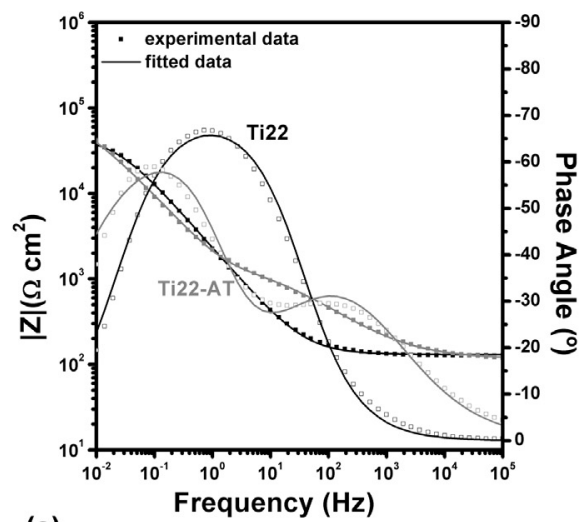

(e)

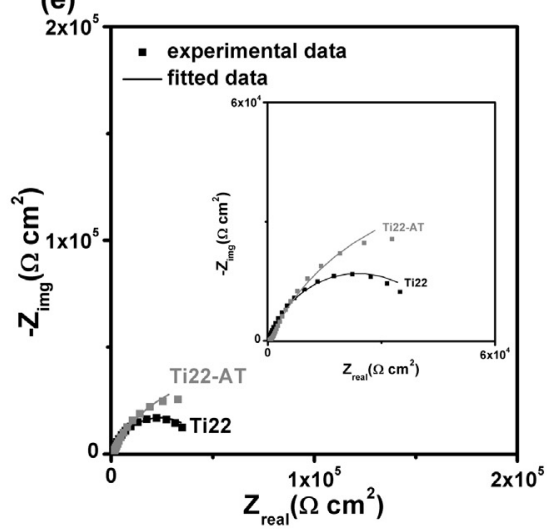

(c)
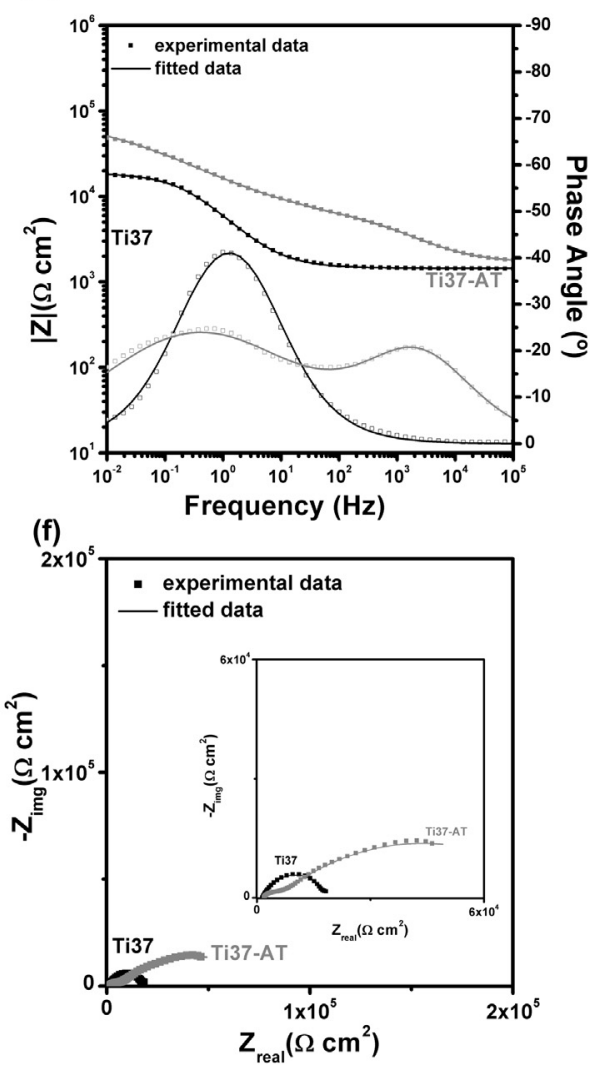

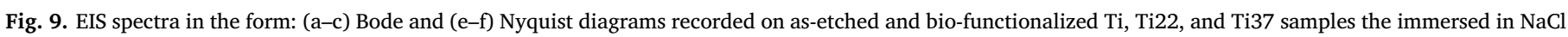
$(9 \mathrm{~g} / \mathrm{L})$ at body temperature.

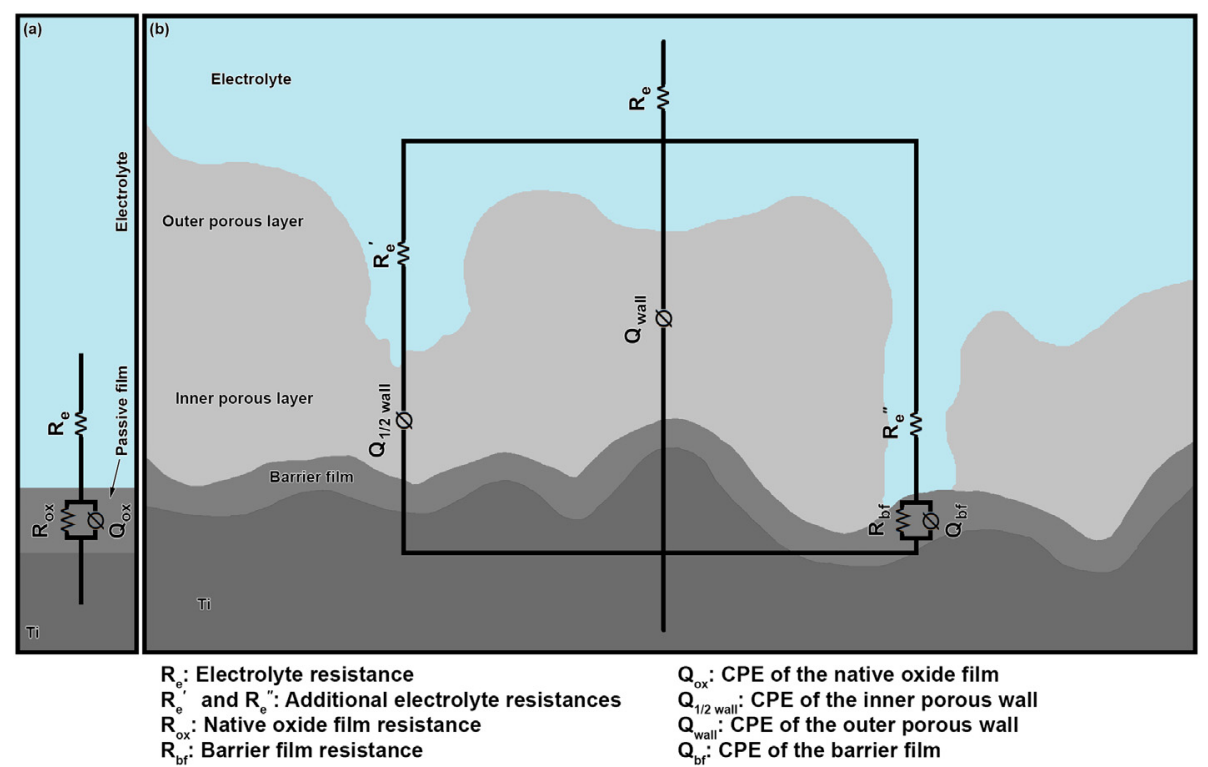

Fig. 10. Equivalent circuit for fitting EIS results for a) as-etched and b) bio-functionalized samples.

samples was improved by the bio-functionalization treatment in terms of thermodynamic and kinetics. The improved corrosion behaviour of bio-functionalized highly porous samples was mostly due to the barrier film formed under longer galvanostatic control during the anodic treatment.

\section{CRediT authorship contribution statement}

A.C. Alves: Conceptualization, Methodology, Validation, Formal analysis, Investigation, Writing - original draft. A.I. Costa: Conceptualization, Methodology, Validation. F. Toptan: Conceptualization, Methodology, Validation, Writing - review \& editing. J.L. Alves: Methodology, Software, Formal analysis. I. Leonor: Methodology. E. Ribeiro: Methodology. R.L. Reis: Methodology. 
Table 3

Equivalent circuit parameters obtained from EIS data for all groups of samples.

\begin{tabular}{|c|c|c|c|c|c|c|c|c|c|}
\hline Samples & $\mathrm{R}_{\mathrm{ox}}\left(\mathrm{M} \Omega \mathrm{cm}^{2}\right)$ & $\begin{array}{l}\mathrm{Q}_{\mathrm{ox}}\left(\mathrm{x} 10^{-5} \mathrm{~F} \mathrm{~cm}^{-2}\right. \\
\left.\mathrm{s}^{\mathrm{n}-1}\right)\end{array}$ & $\mathrm{n}_{\mathrm{ox}}$ & $\begin{array}{l}\mathrm{Q}_{\mathrm{bf}}\left(\mathrm{x} 10^{-5} \mathrm{~F} \mathrm{~cm}^{-2}\right. \\
\left.\mathrm{s}^{\mathrm{n}-1}\right)\end{array}$ & $\mathrm{n}_{\mathrm{bf}}$ & $\begin{array}{l}\mathrm{Q}_{1 / 2 \text { wall }}\left(\mathrm{x} 10^{-6} \mathrm{~F}\right. \\
\left.\mathrm{cm}^{-2} \mathrm{~s}^{\mathrm{n}-1}\right)\end{array}$ & $\mathrm{n}_{1 / 2 \text { wall }}$ & $\begin{array}{l}\mathrm{Q}_{\text {wall }}\left(\mathrm{x} 10^{-6} \mathrm{~F}\right. \\
\left.\mathrm{cm}^{-2} \mathrm{~s}^{\mathrm{n}-1}\right)\end{array}$ & $\mathrm{n}_{\text {wall }}$ \\
\hline $\mathrm{Ti}$ & $0.52 \pm 0.16$ & $4.25 \pm 1.84$ & $0.91 \pm 0.03$ & - & & - & & - & \\
\hline $\mathrm{Ti} 22$ & $0.16 \pm 0.14$ & $7.03 \pm 3.69$ & $0.80 \pm 0.01$ & - & & - & & - & \\
\hline Ti37 & $0.02 \pm 0.01$ & $4.21 \pm 0.97$ & $0.74 \pm 0.02$ & - & & - & & - & \\
\hline Ti-AT & - & - & & $1.26 \pm 0.09$ & $0.85 \pm 0.08$ & $9.59 \pm 2.17$ & $0.80 \pm 0.04$ & $5.74 \pm 2.87$ & $0.71 \pm 0.01$ \\
\hline Ti22-AT & - & - & & $2.06 \pm 0.38$ & $0.73 \pm 0.09$ & $38.81 \pm 3.70$ & $0.82 \pm 0.09$ & $5.43 \pm 0.38$ & $0.72 \pm 0.05$ \\
\hline Ti37-AT & - & - & & $0.52 \pm 0.06$ & $0.84 \pm 0.01$ & $31.87 \pm 1.05$ & $0.76 \pm 0.01$ & $5.73 \pm 0.07$ & $0.73 \pm 0.04$ \\
\hline
\end{tabular}

A.M.P. Pinto: Methodology, Writing - review \& editing, Supervision. J.C.S. Fernandes: Formal analysis, Methodology, Writing - review \& editing, Supervision.

\section{Declaration of competing interest}

The authors declare that they have no known competing financial interests or personal relationships that could have appeared to influence the work reported in this paper.

\section{Acknowledgments}

This work is supported by FCT with the reference project UID/EEA/ 04436/2019, M-ERA NET/0001/2015 project, and Programa de Acções Universitárias Integradas Luso-Francesas' (PAUILF TC-12_14). CQE is financed by FCT under Pluriannual contract 2020-2023. The authors also gratefully acknowledge the "Investissements d'avenir" programs (nos. ANR-11-IDEX-0003-02 and ANR-10- EQPX-37 MATMECA Grant) for financial support on Micro-CT analysis.

\section{References}

[1] A.C. Alves, I. Sendão, E. Ariza, F. Toptan, P. Ponthiaux, A.M.P. Pinto, Corrosion behaviour of porous Ti intended for biomedical applications, J. Porous. Mater. (2016) 1-8.

[2] E. Butev, Z. Esen, S. Bor, In vitro bioactivity investigation of alkali treated Ti6Al7Nb alloy foams, Appl. Surf. Sci. 327 (2015) 437-443.

[3] F. Toptan, A.C. Alves, A.M.P. Pinto, P. Ponthiaux, Tribocorrosion behavior of biofunctionalized highly porous titanium, J. Mech. Behav. Biomed. Mater. 69 (2017) 144-152.

[4] M. Zuldesmi, A. Waki, K. Kuroda, M. Okido, High osteoconductive surface of pure titanium by hydrothermal treatment, J. Biomater. Nanobiotechnol. 4 (2013) 284-290.

[5] Y. Torres, S. Lascano, J. Bris, J. Pavón, J.A. Rodriguez, Development of porous titanium for biomedical applications: a comparison between loose sintering and space-holder techniques, Mater. Sci. Eng. C. 37 (2014) 148-155.

[6] A. Mansourighasri, N. Muhamad, A.B. Sulong, Processing titanium foams using tapioca starch as a space holder, J. Mater. Process. Technol. 212 (2012) 83-89.

[7] Y. Torres, P. Trueba, J.J. Pavón, E. Chicardi, P. Kamm, F. García-Moreno, et al., Design, processing and characterization of titanium with radial graded porosity for bone implants, Mater. Des. 110 (2016) 179-187.

[8] G.G. Lima, G.B. Souza, C.M. Lepienski, N.K. Kuromoto, Mechanical properties of anodic titanium films containing ions of $\mathrm{Ca}$ and $\mathrm{P}$ submitted to heat and hydrothermal treatment, J. Mech. Behav. Biomed. Mater. 64 (2016) 18-30.

[9] C. Simoneau, P. Terriault, B. Jetté, M. Dumas, V. Brailovski, Development of a porous metallic femoral stem: design, manufacturing, simulation and mechanical testing, Mater. Des. 114 (2017) 546-556.

[10] Q. Fu, Y. Hong, X. Liu, H. Fan, X. Zhang, A hierarchically graded bioactive scaffold bonded to titanium substrates for attachment to bone, Biomaterials 32 (2011) 7333-7346.

[11] M.A. Lopez-Heredia, E. Goyenvalle, E. Aguado, P. Pilet, C. Leroux, M. Dorget, et al., Bone growth in rapid prototyped porous titanium implants, J. Biomed. Mater. Res. A 85 (2008) 664-673.

[12] L. Mullen, R.C. Stamp, W.K. Brooks, E. Jones, C.J. Sutcliffe, Selective laser melting: a regular unit cell approach for the manufacture of porous, titanium, bone ingrowth constructs, suitable for orthopedic applications, J Biomed Mater Res B Appl Biomater 89 (2009) 325-334.

[13] B. Li, Z. Li, X. Lu, Effect of the macro-pore structure on the anodic polarization behavior of porous titanium, Anti-Corrosion Methods Mater 59 (2012) 57-62.

[14] Y. Tian, S. Ding, H. Peng, S. Lu, G. Wang, L. Xia, et al., Osteoblast growth behavior on porous-structure titanium surface, Appl. Surf. Sci. 261 (2012) 25-30.

[15] N. Jha, D.P. Mondal, J. Dutta Majumdar, A. Badkul, A.K. Jha, A.K. Khare, Highly porous open cell Ti-foam using $\mathrm{NaCl}$ as temporary space holder through powder metallurgy route, Mater. Des. 47 (2013) 810-819.
[16] L. Bolzoni, T. Weissgaerber, B. Kieback, E.M. Ruiz-Navas, E. Gordo, Mechanical behaviour of pressed and sintered CP Ti and Ti-6Al-7Nb alloy obtained from master alloy addition powder, J. Mech. Behav. Biomed. Mater. 20 (2013) 149-161.

[17] M. Sharma, G.K. Gupta, O.P. Modi, B.K. Prasad, A.K. Gupta, Titanium foam through powder metallurgy route using acicular urea particles as space holder, Mater. Lett. 65 (2011) 3199-3201.

[18] B.Q. Li, C.Y. Wang, X. Lu, Effect of pore structure on the compressive property of porous Ti produced by powder metallurgy technique, Mater. Des. 50 (2013) 613-619.

[19] B. Lee, T. Lee, Y. Lee, D.J. Lee, J. Jeong, J. Yuh, et al., Space-holder effect on designing pore structure and determining mechanical properties in porous titanium, Mater. Des. 57 (2014) 712-718.

[20] S. Amin Yavari, S.M. Ahmadi, J. Van der Stok, R. Wauthle, A.C. Riemslag, M. Janssen, et al., Effects of bio-functionalizing surface treatments on the mechanical behavior of open porous titanium biomaterials, J. Mech. Behav. Biomed. Mater. 36 (2014) 109-119.

[21] K. Kato, S. Ochiai, A. Yamamoto, Y. Daigo, K. Honma, S. Matano, et al., Novel multilayer Ti foam with cortical bone strength and cytocompatibility, Acta Biomater. 9 (2013) 5802-5809.

[22] R. Menini, M.-J. Dion, S.K.V. So, M. Gauthier, L.-P. Lefebvre, Surface and corrosion electrochemical characterization of titanium foams for implant applications, J. Electrochem. Soc. 153 (2006) B13.

[23] F.X. Xie, X.B. He, S.L. Cao, X. Lu, X.H. Qu, Structural characterization and electrochemical behaviour of a laser-sintered porous Ti-10Mo alloy, Corros. Sci. 67 (2013) 217-224.

[24] S.A. Alves, R. Bayón, V.S. de Viteri, M.P. Garcia, A. Igartua, M.H. Fernandes, et al., Tribocorrosion behavior of calcium- and phosphorous-enriched titanium oxide films and study of osteoblast interactions for dental implants, J. Bio- Tribo-Corrosion. 1 (2015) 23.

[25] H.P. Felgueiras, L. Castanheira, S. Changotade, F. Poirier, S. Oughlis, M. Henriques, et al., Biotribocorrosion (tribo-electrochemical) characterization of anodized titanium biomaterial containing calcium and phosphorus before and after osteoblastic cell culture, J Biomed Mater Res B Appl Biomater 103 (2015) 661-669.

[26] A.R. Ribeiro, F. Oliveira, L.C. Boldrini, P.E. Leite, P. Falagan-Lotsch, A.B.R. Linhares, et al., Micro-arc oxidation as a tool to develop multifunctional calcium-rich surfaces for dental implant applications, Mater. Sci. Eng. C. 54 (2015) 196-206.

[27] H. Ishizawa, M. Fujino, M. Ogino, Mechanical and histological investigation of hydrothermally treated and untreated anodic titanium oxide films containing $\mathrm{Ca}$ and P, J. Biomed. Mater. Res. 29 (1995) 1459-1468.

[28] H. Ishizawa, M. Fujino, M. Ogino, Histomorphometric evaluation of the thin hydroxyapatite layer formed through anodization followed by hydrothermal treatment, J. Biomed. Mater. Res. 35 (1997) 199-206.

[29] H. Ishizawa, M. Ogino, Characterization of thin hydroxyapatite layers formed on anodic titanium oxide films containing $\mathrm{Ca}$ and P by hydrothermal treatment, $\mathrm{J}$. Biomed. Mater. Res. 29 (1995) 1071-1079.

[30] H. Ishizawa, M. Ogino, Hydrothermal precipitation of hydroxyapatite on anodic titanium oxide films containing Ca and P, J. Mater. Sci. 34 (1999) 5893-5898.

[31] H. Ishizawa, M. Ogino, Formation and characterization of anodic titanium oxide films containing Ca and P, J. Biomed. Mater. Res. 29 (1995) 65-72.

[32] F.G. Oliveira, A.R. Ribeiro, G. Perez, B.S. Archanjo, C.P. Gouvea, J.R. Araújo, et al., Understanding growth mechanisms and tribocorrosion behaviour of porous $\mathrm{TiO}_{2}$ anodic films containing calcium, phosphorous and magnesium, Appl. Surf. Sci. 341 (2015) 1-12.

[33] I.S. Park, T.G. Woo, W.Y. Jeon, H.H. Park, M.H. Lee, T.S. Bae, et al., Surface characteristics of titanium anodized in the four different types of electrolyte, Electrochim. Acta 53 (2007) 863-870.

[34] D. Quintero, O. Galvis, J.A. Calderón, J.G. Castaño, F. Echeverría, Effect of electrochemical parameters on the formation of anodic films on commercially pure titanium by plasma electrolytic oxidation, Surf. Coatings Technol. 258 (2014) 1223-1231.

[35] A.C. Alves, F. Wenger, P. Ponthiaux, J.-P. Celis, A.M. Pinto, L.A. Rocha, et al., Corrosion mechanisms in titanium oxide-based films produced by anodic treatment, Electrochim. Acta 234 (2017) 16-27.

[36] A.C. Alves, F. Oliveira, F. Wenger, P. Ponthiaux, J.-P. Celis, L.A. Rocha, Tribocorrosion behaviour of anodic treated titanium surfaces intended for dental implants, J. Phys. D. Appl. Phys. 46 (2013) 404001-404009.

[37] I.S. Park, T.S. Bae, K.W. Seol, Surface characteristics of anodized and hydrothermally treated titanium with an increasing concentration of calcium ion, Met. Mater. Int. 12 (2006) 399-406.

[38] H. Ishizawa, M. Fujino, M. Ogino, Mechanical and histological investigation of 
hydrothermally treated and untreated anodic titanium oxide films containing Ca and P, J. Biomed. Mater. Res. 29 (1995) 1459-1468.

[39] L.-H. Li, Y.-M. Kong, H.-W. Kim, Y.-W. Kim, Improved biological performance of Ti implants due to surface modification by micro-arc oxidation, Biomaterials 25 (2004) 2867-2875.

[40] L. Benea, E. Mardare-Danaila, M. Mardare, J.-P. Celis, Preparation of titanium oxide and hydroxyapatite on Ti-6Al-4V alloy surface and electrochemical behaviour in bio-simulated fluid solution, Corros. Sci. 80 (2014) 331-338.

[41] M. Teixeira, A.C. Alves, F.S. Silva, A.M.P. Pinto, F. Toptan, Microstructural characterization of biofunctionalized titanium foams, Microsc. Microanal. 21 (2015) $55-56$.

[42] X. Fan, B. Feng, J. Weng, J. Wang, X. Lu, Processing and properties of porous titanium with high porosity coated by bioactive titania nanotubes, Mater. Lett. 65 (2011) 2899-2901.

[43] A.C. Alves, R. Thibeaux, F. Toptan, A.M.P. Pinto, P. Ponthiaux, B. David, Influence of macroporosity on NIH/3T3 adhesion, proliferation, and osteogenic differentiation of MC3T3-E1 over bio-functionalized highly porous titanium implant material, J. Biomed. Mater. Res. Part B - Appl. Biomater. (2019) 73-85.

[44] J.J. de Damborenea, M.A. Larosa, M.A. Arenas, J.M. Hernández-López, A.L. Jardini, M.C.F. Ierardi, et al., Functionalization of Ti6Al4V scaffolds produced by direct metal laser for biomedical applications, Mater. Des. 83 (2015) 6-13.

[45] S. Virtanen, I. Milosev, E. Gomez-Barrena, R. Trebse, J. Salo, Y.T. Konttinen, Special modes of corrosion under physiological and simulated physiological conditions, Acta Biomater. 4 (2008) 468-476.

[46] A. Mathis, E. Rocca, D. Veys-Renaux, J. Tardelli, Electrochemical behaviour of titanium in KOH at high potential, Electrochim. Acta 202 (2016) 253-261.

[47] Y. Wang, T. Lei, B. Jiang, L. Guo, Growth, microstructure and mechanical properties of microarc oxidation coatings on titanium alloy in phosphate-containing solution, Appl. Surf. Sci. 233 (2004) 258-267.

[48] F. Xie, X. He, S. Cao, M. Mei, X. Qu, Influence of pore characteristics on microstructure, mechanical properties and corrosion resistance of selective laser sintered porous Ti-Mo alloys for biomedical applications, Electrochim. Acta 105 (2013)
$121-129$.

[49] G. Xie, F. Qin, S. Zhu, D.V. Louzguine-Lugzin, Intermetallics corrosion behaviour of porous Ni-free Ti-based bulk metallic glass produced by spark plasma sintering in Hanks' solution, Intermetallics 44 (2014) 55-59.

[50] J. Fojt, L. Joska, J. Málek, Corrosion behaviour of porous Ti-39Nb alloy for biomedical applications, Corros. Sci. 71 (2013) 78-83.

[51] K.H.W. Seah, R. Thampuran, S.H. Teoh, The influence of pore morphology on corrosion, Corros. Sci. 40 (1998) 547-556.

[52] K.H.W. Seah, X. Chen, A comparasion between the corrosion characteristics of 316 stainless steel, soldi titanium and porous titanium, Corros. Sci. 34 (1993) 1841-1851.

[53] X. Chen, Q. Fu, Y. Jin, M. Li, R. Yang, X. Cui, et al., In vitro studying corrosion behavior of porous titanium coating in dynamic electrolyte, Mater. Sci. Eng. C. 70 (2017) 1071-1075.

[54] D.J. Blackwood, A.W.C. Chua, K.H.W. Seah, R. Thampuran, S.H. Teoh, Corrosion behaviour of porous titanium-graphite composites designed for surgical implants, Corros. Sci. 42 (2000) 481-503.

[55] B.J. Edwards, P. Higham, Anodic polarisation of porous coated vitalhum alloy effect of passivation, ASTM-STP (1987) 115-123.

[56] B. Dabrowski, W. Swieszkowski, D. Godlinski, K.J. Kurzydlowski, Highly porous titanium scaffolds for orthopaedic applications, J. Biomed. Mater. Res. - Part B Appl. Biomater. 95 (2010) 53-61.

[57] S.B. Basame, H.S. White, Pitting corrosion of titanium the relationship between pitting potential and competitive anion adsorption at the oxide film/electrolyte interface, J. Electrochem. Soc. 147 (2000) 1376-1381.

[58] M.E. Orazem, B. Tribollet, Electrochemical Impedance Spectroscopy, 2nd Ed, Jonh Wiley \& Sons, New Jersey, 2017.

[59] E.M. Szesz, B.L. Pereira, N.K. Kuromoto, C.E.B. Marino, G.B. de Souza, P. Soares, Electrochemical and morphological analyses on the titanium surface modified by shot blasting and anodic oxidation processes, Thin Solid Films 528 (2013) 163-166.

[60] S. Ikonopisov, Theory of electrical breakdown during formation of barrier anodic films, Electrochim. Acta 22 (1977) 1077-1082. 